\title{
Print-Based Learning Media
}

Emanuel Mayembe ${ }^{1}$, Shemme Nsabata ${ }^{1}$

${ }^{1}$ Department of Primary Education, University of Zambia, Zambia

*Corresponding Author: Patson Emanuel Mayembe

\begin{abstract}
The purpose of this paper is to identify about the print-based media learning. The paper discusses about the development, characteristic, types and the advantages disadvantages of the print based media learning. In a teaching and learning process, two very important elements are teaching methods and learning media. These two aspects are interrelated. The choice of a particular teaching method will affect the appropriate type of learning media, although there are various other aspects that must be considered in choosing learning media, including learning objectives, types of tasks and responses expected by students and student characteristics. Even so, it can be said that one of the main functions of learning media is as a teaching aid that influences the climate, conditions, and learning environment that are organized and created by the teacher.
\end{abstract}

Keywords: Print-based, Media, Learning, Teaching

Introduction

Learning media in the teaching and learning process can generate new interests and desires, generate motivation and stimulation of learning activities, and even bring psychological influences on students. The use of learning media at the teaching orientation stage will greatly assist the effectiveness of the learning process and the delivery of messages and lesson content at that time. Learning media has various kinds that need to be understood by education, one of which is print-based mesis. Based on his clarification, the second media (after human-based media) is called print-based media. This printed learning media has very clear characteristics including writing. As an educator, it is very important to understand print-based media because this media is very commonly used in the teaching and learning process. Thus, in this paper we will discuss print-based media. Print media is a well-known mass media, printed media is also a written medium or means of communication. There are various kinds of media that are classified into print media. Such as books, modules, newspapers, magazines, articles and so on. In the application of print-based media in learning, it can support or assist students and educators in explaining metrics and using teaching methods or techniques. The use of print-based media itself is widespread and is still used today.

\section{History of Print Media}

Fussel (2020) stated that print media was first discovered in 1455 in European countries, the inventor was named Johannes Gutenberg. At the beginning of the development of print media, leaves and clay were used as a printing medium. Through the printing technology invented by Gutenberg, He started printing Bibles. Thanks to this printing machine 
technology, the number of books produced is not small. At the beginning of the development of print media, which was accompanied by not yet developing technology, print media at that time was made using typewriters to make advertisements for a product. The pictures or animations in the advertisement are made with pen manually. The signs of the development of print media are indicated by the ability to read and write or it can be called literacy. Literacy is a condition that only the elite know about it. Languages that have developed are only a few basic languages such as Latin. In the 14th century, the development of education also encouraged the development of literacy in society. Currently, the development of print media is accompanied by developments in technology that have already developed, making it easier for people to create various and varied products or animations. From the development of existing technology, there are changes in print media such as the shape, format, structure, texture, and model of a product. However, technological developments do not affect or change the content of a product that appears in the media.

Technological developments in print media related to the development of print media itself, such as the emergence of newspapers, newspapers, magazines that contain politics, culture, literature, public opinions, public health can color life (Starr, 2004).

\section{Definition of Print Media}

Print materials are also known as Print Technology, or print media. According to Prytherch (2016) printed materials are all forms of publications, documents, or a note in the form of newspapers, magazines, pamphlets, books, photos, pictures, transcriptions of magnetic tapes, and various other forms of printed materials. This media can be found anywhere and anytime and we can reach it in the nearest shops at a relatively cheaper cost. In everyday life, print media is related to printing. Print media here is more directed at the field of communication related to the dissemination of information to meet the needs of the community or the masses. Therefore, the print media tends to be called part of the mass media whose role is to gather various information, process, print, and disseminate it.

According to Reitz (2004) in the field of education, print media in Education, is a world-wide program hereby newspapers and magazines are used to promote education in school classrooms (Print media in education is a program that is widespread throughout the world such as letters newspapers and magazines used to promote education in the classroom). From this definition, print media can be interpreted as a means or container for disseminating information about education. Printed learning materials are printed textbooks and printed core materials that are relevant written and published for use in learning needed by the central and local governments used by students in learning. These materials include workbooks and other supplementary materials that are packaged for textbooks by a publisher.

The development of printed materials is a way to convey printed materials such as books, and static visual materials, especially through a mechanical printing process or the development of printed materials can be seen as a way of producing and presenting printed materials in text and visual form. Based on the above definition, it can be concluded that printed materials / media in education are all printed forms such as text books, modules, worksheets, articles, journals, newspapers, magazines and various other forms of printed materials used in learning needs that function as intermediaries for sources of information either from the teacher or lecturer to the recipient of the information, namely students. The printed materials in question include: (1) Presentation of materials in text and visual form. (2) 
Publications, text books, modules, worksheets, handouts, newspapers, articles, magazines, pamphlets, books, photos, pictures, magnetic tapes. (3) Media networks, such as newspapers and journals.

Print-based learning media that are often used or most commonly known are text books, handbooks, workbooks or exercises, journals, magazines, and handouts.

\section{Characteristics of Print Media in Learning}

(1) The delivery of a message printed on paper. (2) Displayed silently, unchanged, motionless, or silent. (3) Text is read from one direction, such as with a two-dimensional work of art that can only be seen from one direction only. (4) It is flexible, easy to carry everywhere and can be read anytime without being bound by time. (5) Showing receptive communication (open to opinions / accept suggestions). Social criticism conveyed by printed media will be more effective because it is discussed in depth and can accommodate many opinions from critics. (6) Reading stimulates people to actively think and digest creatively, thus opening up opportunities for dialogue with readers in addition to allowing for detailed and specific review of problems (Fhay, 2004).

\section{Types of Print-Based Educational Media}

According to Hwang et al. (2014 various educational media are starting to be found in the world of education at this time, one of which is print-based media. As for the types of printed media, Kemp and Smelle are divided into three groups, namely: (1) Learning aids, this study aid includes resources designed for the independent learning needs of students who follow instructions to perform specific tasks. In particular, study aids consist of work guides, as well as work aids and serial drawings. (2) Training materials, for example, handout sheets that are more informative than procedural. In addition, the training material also contains a study guide which is a series of pages to direct the trainees in completing assignments. The instructor's manual is also a training material. (3) Informational training, brochure that serves as an announcement of a program and the type of service offered.

There is also the development of print learning media such as: (1) Textbook, textbookis a manual for the learning process that covers various topics from certain fields that are usually associated with the curriculum. Textbooks can also be referred to as study guides specially designed with subjects or courses that contain content that must be studied within a certain period of time. Other terms that are often used and refer to books are novels, dictionaries, comics, encyclopedias, holy books, biographies, and manuscripts or manuscripts, all of which can be used to support teaching materials and learning resources. In textbooks used in learning there are also advantages and disadvantages. Some of the advantages of textbooks are as follows: (a) Availability: Even though high quality books are hard to find, the availability of printed books is still very easy to find either in stores or can be downloaded at certain sites. (b) Flexible: Writing is very easy to adapt to specific needs and goals as well as with the surrounding environment. (c) Easy to use: Using textbooks is very easy to use by students inside and outside the classroom by directing them directly: (a) to students to read and do assignments using the book. (b) Economical: Printed books are relatively inexpensive.

Apart from having advantages, textbooks also have the following disadvantages: (a) Readability: the main difficulty of textbooks because they are written based on a certain reading level. Many students are not accustomed to reading and do not have reading skills so that the obstacles of students are less able to understand it. (b) Memorization: Many 
teachers use a rote system to understand certain concepts and definitions. While the author of the book, there is no best way used to master the concept without going through rote memorization and there are no tools to make it easier for students to memorize the concepts in question. (c) Vocabulary: The use of a lot of vocabulary in text books sometimes makes it difficult for students to understand it. (d) Curriculum Oriented: Textbooks are accommodated based on the curriculum, so that there is an imbalance between the content contained in the textbook and the treatment experienced in the learning process, even if the curriculum is complete and does not care about the complete mastery of students. (e) Cursory assessment: Textbooks sometimes do not go through a careful selection process. In schools, the use of textbooks tends to be dominated by the intensity of the approach taken by book agents towards teachers in school. (f) One-way presentation: Textbooks only provide information that is read only in one direction, not interactive which allows students to interact. Textbooks do provide information that can only be understood if they are read, analyzed and explored further. According to Carnet (2013) in writing textbooks, it is necessary to consider the structure in a book which includes several aspects such as content, introduction or introduction, chapters or units, keywords, bibliography.

\section{Learning Module}

The learning module is an independent learning package that is arranged systematically to facilitate the learning experience of students in order to achieve learning objectives. By using a good module, learning can reach students including the various characteristics they have. Before developing a learning module, there are several characteristics of a good module including: (a) Preceded by a statement of learning objectives. (b) Knowledge is structured in such a way that it can invite active student participation. (c) Contains a grading system based on mastery. (d) Contains all elements of study material and all lesson assignments. (e) Provide opportunities for differences between individual students. ( $f$ ) Leads to a complete learning goal. Then in the development of the learning module there are seven suggested procedures (Hasyim: 1999: 343), namely making rationalization, designing general goals, writing specific objectives, compiling prerequisite tests, compiling multimedia materials, designing learning activities, compiling independent tests, providing final tests.

\section{Worksheet}

Student worksheets are printed learning materials which contain several series of assignments, study instructions, and task completion procedures. Worksheets can be designed online and electronically in the form of assignments that support the development of learners' knowledge, attitudes and skills.

\section{Handouts}

Handout is a summary in printed learning which contains concept mapping, brief descriptions, summaries, schemes, work procedures or application of formulas etc. So handouts or freelance sheets are printed teaching materials given to students which contain the essence of the discussion, questions and problems, and assignments to be completed by students.

\section{Articles}

Articles can be understood as scientific papers which are constructed from the results of research and studies to be published in scientific journals and magazines. Articles are 
included in printed media although they can be accessed online. Articles that are printed in the form of a printed journal are said to be printed teaching materials because they can be used as references in carrying out learning.

\section{Newspapers}

Newspapers are serial publications containing news about special and general events. Topics can be in the form of political events, crime, sports, editorials, weather and certain news. Newspapers also usually contain caricatures which are usually used as satire through pictures relating to certain issues, comics, crosswords etc. (Wikipedia, 2015). Therefore, newspapers contain the latest news, so it is often used as a teaching material, both in the form of clippings and in the form of sheets which are cut into pieces according to learning needs and from the news that is published it can be used as the chosen learning resource. based on its relevance to a particular subject.

\section{Poster}

A poster is a graphic design which contains a composition of images and letters on large paper. Posters can be used to learn as examples or models in conveying messages effectively if they are formed with a combination of text, images, and colors to attract students' interest.

\section{Comics}

Comics are a form of art that uses immovable images and is arranged in such a way as to form a storyline. Comics are very effective when applied to early childhood such as kindergarten or elementary school. Comics can be applied to children who are dominant in language and visual intelligence because they contain colorful images. Comics that have been printed and published in newspapers can be used as clippings to be used as printed teaching materials to support lessons.

\section{Elements of Print-Based Media}

In print-based media, there are six elements that are important and must be included in the printed learning media, including: (1) Consistency or constancy in implementing print-based learning that needs to be considered is the most important consistency. Components in consistency or consistency include: (a) Use consistent formatting from page to page. Attempts were made not to combine print and font sizes. (b) Try to be consistent in spacing. The distance between the title and the first line and the line side to match, and between the title and main text. Unequal spaces are always considered bad, untidy, and therefore do not require real attention. (2) Format, in print-based media format elements is very important and necessary because: (a) When long paragraphs are used too often, one column faces are more appropriate; conversely, if the paragraph is written short then a two-column face is more appropriate. (b) The different contents should be separated and labeled visually. (c) Tactics and strategies in different learning should be separated and labeled visually ( McClune \& Jarman, 2011).

\section{Organization}

Organizational elements on print-based media can include the following: (a) Try to always inform students or readers about the extent of abilities they have in the text. Students must be able to glimpse the section or chapter they are reading. If possible, prepare a tool that is able to orient students about their position in the text as a whole. (b) Arrange the text in a 
way that allows information to be easily obtained quickly. (c) Grid boxes can be used to separate sections of text.

\section{Attraction}

Introduced in each new chapter or section in a different way, this is expected to motivate students to read continuously.

\section{Font size}

For elements in print-based media, the font size is very important as in the following explanation: (a) Choose a font size that suits the student, the message and the environment. The font size can usually be specified with a font size of 24 points per inch, for example. A good font size in text or a book is 12 points. (b) It is avoided to use capital letters throughout the text because it makes it difficult for the reader to find the reading process.

\section{Blank space or space}

One of the elements in print-based media is blank space or space. (a) Use blank spaces that contain no image / text for added contrast. It is important to give students a break at some point. As his eyes traced the text. The free space can take the form of: (1) Space around the title. (2) Margins. (3) Space between columns. (4) Beginning of paragraphs. (5) Adjustment of spacing between lines / paragraphs. (b) Adjust the spacing between the lines to increase the appearance and readability. (c) Add space between paragraphs to improve appearance and readability.

\section{Advantages and Disadvantages of Print Media}

The advantages of print-based media: (1) Able to convey various information related to facts and abstract concepts that are knowledge, skills or attitudes. (2) Can be used anytime (morning, noon, night) and anywhere (such as at home, in public vehicles, terminals or other possible places). (3) Easy to use, independent of other equipment. Print media packaging is generally light and small easy to take them wherever they go. (4) Besides the physical form is easy to carry, the arrangement or presentation technique of the material is also easy to learn. For example, presentation techniques such as index writer, table of contents, use of pages, chapters, titles and subheadings. Lack of print-based learning media: (1) Difficulty displaying motion on the printed media page. (2) Printing costs will be expensive if you want to display colorful illustrations, pictures, or photos. (3) The media printing process often takes several days to months, depending on the printing equipment and the complexity of the information on the printed pages. (4) The division of study units in printed media must be designed in such a way that they do not go over long and can be boring. (5) Generally print media produces good results if the lesson objectives are cognitive, for example learning about facts and skills. (6) If not properly maintained, printed media can quickly become damaged and lost. (7) Bold printed material may be boring and turn off students' interest in reading it (Cloeta et al. 2003).

\section{Conclusion}

According to (DRC Ohio State, 2003) printed materials are all forms of publications, documents, or notes in the form of newspapers, magazines, pamphlets, books, photos, pictures, transcriptions of magnetic tapes, and various other forms of printed materials. The types of print media are Learning aids (learning aids), training materials (training materials), and informational training (information materials). The characteristics of print media in 
learning, namely, the delivery of a message printed on paper, displayed silently and unchanged, the text in the media is read from one direction, this printed media is flexible in displaying receptive communication. The advantages of print media include; Cheap / relatively inexpensive, accessible to the wider community, does not require equipment, is flexible. Besides that, the weaknesses are that in terms of time the print media is slow in providing information, it requires reading habits, requires prior knowledge, if the presentation (fonts, colors, illustrations) is not attractive it will get boring quickly, the manufacturing process takes a long time. long enough, thick printed materials may be boring so that it discourages students from reading them, and printed materials will be easily damaged and torn. The suggestion is that the writer is expected to add more references so that the insight becomes wider related to print-based learning media. Hopefully in the future this paper can be used as a reference in finding material about print-based learning media.

\section{References}

Cloete, L. M., Snyman, R., \& Cronjé, J. C. (2003, October). Training cataloguing students using a mix of media and technologies. In Aslib Proceedings: new information perspectives (Vol. 55, No. 4, pp. 223-233). Emerald Group Publishing Limited.

Fahy, P. J. (2004). Media characteristics and online learning technology. Athabasca University Press.

Füssel, S. (2020). Gutenberg and the Impact of Printing. Routledge.

Hwang, Y., Kim, H., \& Jeong, S. H. (2014). Why do media users multitask?: Motives for general, medium-specific, and content-specific types of multitasking. Computers in Human Behavior, 36, 542-548.

McClune, B., \& Jarman, R. (2011). From aspiration to action: A learning intentions model to promote critical engagement with science in the print-based media. Research in Science Education, 41(5), 691-710.

Prytherch, R. (2016). Harrod's librarians' glossary and reference book: a directory of over 10,200 terms, organizations, projects and acronyms in the areas of information management, library science, publishing and archive management. Routledge.

Reitz, J. M. (2004). Dictionary for library and information science. Libraries Unlimited.

Starr, P. (2004). The creation of the media: Political origins of modern communications (p. 417). New York: Basic Books. 